\title{
Estilística e estilo no Círculo de Bakhtin e no Idealismo Alemão: um estudo comparativo entre as bases dialógica e monológica na ciência da linguagem
}

\author{
Taciane Domingues ${ }^{1}$ \\ Universidade de São Paulo (USP), São Paulo, São Paulo, Brasil \\ tacianedomingues@gmail.com \\ https://orcid.org/0000-0001-5056-3512
}

DOI: http://dx.doi.org/10.21165/el.v47i2.1914

\begin{abstract}
Resumo
Neste artigo, contrapusemos a noção de estilo e estilística de Karl Vossler, representante máximo da Idealistische Neuphilologie (Filologia Idealista Moderna), à do Círculo de Bakhtin, com apoio em obras de Mikhail M. Bakhtin e Valentin N. Volóchinov. Elegemos dois conceitos-chave de ambas vertentes para discorrer sobre as bases monológica e dialógica de seus métodos: o monólogo autoral, presente na concepção de Vossler e enraizado em sua herança romântica e idealista, e o heterodiscurso social, cunhado por Bakhtin segundo bases dialógicas. Com esses conceitos em foco, comparamos análises estilísticas feitas por Vossler e por Bakhtin e ressaltamos que suas diferenças sinalizam uma transição na investigação linguística, sendo a mais fundamental que o dialogismo trouxe à análise estilística a concepção do romance não mais como uma obra que mostra o gosto linguístico, a originalidade e o gênio criativo de seu autor, mas sim como a representação ou imagem de uma língua permeada por visões ideológicas contraditórias.

Palavras-chave: Círculo de Bakhtin; idealismo; estilo; estilística; linguística.
\end{abstract}

Stylistics and Style in the Bakhtin Circle and the Idealism: a comparative study between the dialogical and monological basis in Linguistics

\begin{abstract}
The proposition of this article is to compare the notion of Style and Stylistics from Karl Vossler, one of the greatest names from the Idealistische Neuphilologie (Modern Idealist Philology), to that from the Bakhtin Circle, based on Mikhail M. Bakhtin and Valentin N. Voloshinov's writings. From these authors, two keywords were chosen to best summarize the monological and dialogical basis of their respective methods: the authorial monologue, presented in Vossler's conception of Style and Stylistics and deeply rooted in his romantic and idealist heritage, and the social heterodiscourse, described by Bakhtin according to dialogical notions of Style and Stylistics. Focusing on these key words, Vossler and Bakhtin's analysis on literary texts were compared. The results point out to a transition in the Linguistics, in which the dialogical conception of Style and Stylistics brought up the literary work as a representation of a language that is not unique but merged from contradictory ideologies, instead of it being a sample of a particular author's peculiarities.
\end{abstract}

Keywords: Bakhtin Circle; Idealism; Style; Stylistics; Linguistic.

\footnotetext{
${ }^{1}$ Apoio: FAPESP (Processo: 2017/25085-0)
} 


\section{Introdução e objetivos}

Neste artigo, investigaremos a noção de estilo de duas vertentes de teorias estilísticas: da sociológica, do Círculo de Bakhtin, e da idealista, de Karl Vossler. O método sociológico da vertente marxista trouxe, através do conceito "heterodiscurso social", a dimensão dialógica à questão do estilo no romance, opondo-se ao olhar predominantemente monológico da escola de Vossler. Este, por sua vez, herdou o discurso romântico da originalidade na produção linguística que, segundo diz, sintonizase com os parâmetros da criação artística em geral.

De obra de arte enquanto expressão do estilo linguístico individual, o romance passa a ser, para os teóricos do Círculo, o espaço onde a prosa consegue representar e concatenar os variados discursos sociais (línguas sociotípicas), ou seja, as variadas línguas do cotidiano, da ideologia (arte, ciência, religião etc.), das profissões e dos gêneros, sinalizando uma transição do olhar monológico sobre a produção literária para o dialógico.

Nestas páginas, abordaremos as diferenças na concepção de estilística dessas duas vertentes segundo aquilo que denominamos "monólogo autoral" - termo que pretende sintetizar a base monológica permeada pelo romantismo, que por sua vez teve influência do idealismo, presente em Vossler - e a base dialógica, fruto do método sociológico russo, explorando seu conceito de heterodiscurso social.

Por fim, esperamos oferecer uma discussão sobre a comparação da noção de estilo e de estilística das duas escolas, assim como contribuir para a discussão sobre as diferenças entre uma abordagem monológica e uma dialógica na investigação linguística. Acreditamos que o método sociológico na ciência da linguagem é um dos que representa esta transição ao afirmar, em Marxismo e filosofia da linguagem: problemas fundamentais do método sociológico na ciência da linguagem (doravante MFL), "suponhamos que aqui, como sempre, a verdade não se encontre no meio-termo nem seja um compromisso entre a tese e a antítese, ficando fora e além dos seus limites, e negando tanto a tese quanto a antítese, ou seja, representando uma sintese dialética". ${ }^{2}$

\footnotetext{
${ }^{2}$ Nos anos de 1920, Bakhtin e Volóchinov, autores do denominado Círculo de Bakhtin, lançam o método sociológico nos estudos linguísticos como um projeto comum que é realizado de maneiras diferentes: por Volóchinov na filosofia da linguagem e por Bakhtin na Estilística e Teoria Literária. Apesar de haver um capítulo em MFL que trata do discurso do outro no romance, Volóchinov afirma no prólogo ser esta uma obra inicial sobre a abordagem marxista na linguística (2017[1929]), p. 87). Entendemos que a obra de Bakhtin Teoria do romance I: A Estilística (2015) aprofunda as questões do discurso citado propostas em MFL na forma do heterodiscurso social, de modo que usamos ambas as obras como complementares uma da outra no tocante ao projeto dialógico do Círculo. Ainda sobre o tema, ver Puzzo (2017), "Dialogismo bakhtiniano e a estilística vossleriana", no qual a autora, por caminhos diferentes, chega a conclusões semelhantes sobre este momento de transição no pensamento linguístico.
} 


\section{Justificativa e metodologia}

Em MFL, Volóchinov ${ }^{3}$ lança uma filosofia da linguagem apoiada no método sociológico, que é apresentado como a síntese dialética resultante do confronto entre a tese (escola monológica de Vossler) e a antítese (Escola de Genebra, que se dedicou a seguir as bases do pensamento linguístico proposto por Saussure). Nessa obra, o autor russo afirma que a escola de Karl Vossler é herdeira do movimento romântico alemão, e tal herança se reflete na base monológica de sua concepção de estilo:

A primeira tendência - o subjetivismo individualista (Idealistische Neuphilologie, ou Filologia Idealista Moderna) - está ligado ao Romantismo. [...] Os românticos foram os primeiros filólogos da língua materna, os primeiros a tentar reconstruir radicalmente o pensamento linguístico na base das vivências da língua materna, vista como medium de formação da consciência e do pensamento. [...]

Entretanto, o subjetivismo individualista também considerava o enunciado monológico enquanto a última realidade, isto é, o ponto de partida do seu pensamento sobre a linguagem. É verdade que eles a abordavam não do ponto de vista de um filólogo que compreende passivamente, mas como se fosse de dentro, do ponto de vista do próprio falante que se expressa.

O que seria então o enunciado monológico do ponto de vista do subjetivismo individualista? - Como observamos, ele é um ato puramente individual, uma expressão da consciência individual, dos seus propósitos, intenções, impulsos criativos, gostos e assim por diante. A categoria da expressão é aquela categoria superior e geral à qual é reduzido o ato linguístico, isto é, o enunciado. (VOLÓCHINOV, 2017[1929], p. 202, grifos meus).

Para abrir uma discussão sobre as diferenças na concepção de estilo e estilística de ambas escolas e sinalizar o momento da transição do olhar predominantemente monológico de uma para o dialógico da outra, buscaremos primeiramente formar um quadro sólido da Filologia Idealista Moderna que fosse confrontável com as afirmações acima.

Para tanto, recorreremos a escritos de Vossler, seu principal representante, sobre sua filosofia da linguagem, a fim de encontrar passagens que comprovem ou refutem as afirmações contidas em MFL e aqui reproduzidas. Investigamos: i) o caráter monológico da concepção de estilo e estilística do autor, segundo o afirmado por Volóchinov e ii) marcas do pensamento romântico na Filologia Idealista Moderna. A primeira seção deste artigo será dedicada a estes tópicos.

Posteriormente, avançamos para a segunda seção: a definição do conceito "heterodiscurso social" de Mikhail Bakhtin. Começaremos explicando a relação que Bakhtin estabelece entre a coexistência de diversas línguas sociotípicas entre si e com a língua "oficial" de uma nação e o heterodiscurso social no romance, pois ambos tópicos estão estreitamente relacionados e expressam em si a dialogicidade do método sociológico em geral e nas questões de estilística. Após aclararmos o que é o

\footnotetext{
${ }^{3}$ Não é o foco deste artigo entrar nas questões de autoria que permeiam os estudos sobre o Círculo de Bakhtin. Apesar de não ignorarmos essa discussão, para não adentrá-la manteremos simplesmente a assinatura desta obra da forma como foi lançada na tradução brasileira diretamente do original russo. Nela, Volóchinov figura como o autor, do mesmo modo que na primeira edição russa de 1929.
} 
heterodiscurso social segundo Bakhtin, partiremos para a análise aqui proposta: as questões de estilo e estilística segundo as duas vertentes, que se contrapõem pelas bases monológica e dialógica. A terceira seção do artigo é dedicada a delinear essa contraposição.

Nossa metodologia consistiu em confrontar passagens coletadas da obra de Karl Vossler que evidenciam as características daquilo que denominamos "monólogo autoral" - a saber, a ênfase dada por ele à questão do estilo autoral criativo e exclusivo (original) na produção linguística, tanto literária quanto geral - com passagens de Bakhtin que expõem sua visão dialógica da questão estilística no romance, em particular, e dialógica discursiva, em geral. As passagens de Bakhtin selecionadas focam na definição do "heterodiscurso social", conceito que exprime a representação, na estrutura narrativa do romance, da coexistência das várias línguas sociotípicas - que, por sua vez, são variações formais e discursivas que coexistem com a língua "oficial" de uma nação.

Abrimos a primeira seção traçando um panorama das principais ideias do filólogo Karl Vossler acerca de sua investigação linguística. Esse panorama nos introduzirá com mais propriedade nas questões do monólogo em seu pensamento e dará sustentação à nossa adjetivação "autoral".

\section{O monólogo autoral de Karl Vossler e a Filologia Idealista Moderna}

Seguindo nossa metodologia, a primeira seção deste artigo visa formar um quadro sólido da Filologia Idealista Moderna que possa ser comparável àquele oferecido em MFL, respondendo aos questionamentos propostos na seção introdutória. Comecemos por um pequeno resumo das principais ideias de Vossler.

A Filologia Idealista Moderna desenvolveu-se a partir de estudos filológicos em língua materna (alemão) e línguas românicas. Pela forte presença da filologia nesta escola, a literatura, ou seja, o documento escrito, foi a principal fonte para a investigação e reflexão linguística dos estudiosos desta vertente. O próprio Karl Vossler foi filólogo e romanista de formação e desenvolveu uma filosofia da linguagem baseada na investigação das motivações que, para ele, verdadeiramente impulsionavam as mudanças linguísticas, definindo como escopo de sua pesquisa a produção e a consciência individuais do falante e do autor literário.

Segundo ele, as mudanças linguísticas, evidenciadas na plasticidade das formas das línguas, eram resultantes sobretudo das escolhas estilísticas do falante/autor face às ofertas linguísticas fornecidas pelo cenário político, econômico, cultural etc. Vossler não concebia a língua como material social construído e validado pela interação entre indivíduos, mas como uma matéria plástica sendo constantemente moldada por cada indivíduo isoladamente segundo seu gosto e até mesmo gênio artísticos (caso de grandes autores), em posse da gramática enquanto sua técnica e do gosto linguístico enquanto seu critério.

A técnica gramatical, segundo o teórico alemão, não tinha por referência normas validadas no seio da interação social: tinha por referência a si mesma enquanto técnica, sendo comparada àquela da pintura e da música. O gosto linguístico, apesar de admitir um caráter mais social, podendo ser aprendido e ensinado, não chegava a ser concebido como fruto da interação social, pois ainda colocava o poder de atuação exclusivamente no falante. Vossler concebia, inclusive, o elemento do gênio original, característica que 
não poderia ser aprendida nem ensinada. A figura do gênio representava o máximo da concepção individualizante do sujeito e da língua e, portanto, do olhar monológico autoral:

[...] toda técnica tem em si mesma seu ideal, a saber, a medida de sua conformidade - não fora dela, nem acima dela. [...] Onde quer que haja uma técnica específica, há um pensamento específico, uma ideia específica. A técnica de um pintor está a serviço do pensamento pictórico, a do músico, do pensamento musical. Daí concluímos ser a gramática a técnica da língua, a serviço apenas do pensamento linguístico, não do lógico. (VOSSLER, 1923, p. 5, tradução minha).

Agora sabemos a serviço de que está o ensino do gramaticalmente correto (a gramática prática). Ele está a serviço da língua enquanto arte; ensina-nos a técnica do linguisticamente belo. [...]

Sob "gosto linguístico" compreendemos o caráter imitativo, seletivo e reprodutivo assim como o tino artístico inventivo e criativo. O gosto linguístico pode e necessita ser ensinado; o gênio criador não - pelo menos não enquanto produz algo original. Em termos concretos, a saber, na prática cotidiana, encontramos criações artísticas, gostos linguísticos e gênios num curso perpétuo e indissociável de produção e reprodução. Imitação e originalidade, obras-primas e insignificantes estão por todo lugar. $\mathrm{O}$ trabalho do crítico de arte é distingui-las. (idem, p. 15, tradução minha) ${ }^{4}$.

Adiante, reproduzimos um exemplo prático dado pelo próprio Vossler para ilustrar como ele realiza o recorte monológico e interpreta dados deste recorte como característicos da escolha individual, apoiada no gosto linguístico em detrimento da interação social:

Quando um alemão toma de empréstimo uma expressão do inglês como "made in Germany" e o incorpora a seu falar, isso acontece por razões de duas ordens distintas: uma série causal prática e uma estética. Os motivos práticos são aqueles que aproximaram e ofereceram a expressão inglesa à língua alemã. São as forças da grande concorrência econômica que a humanidade tem presenciado. Contudo, sozinha, nem toda a potência mundial da Inglaterra nem a mais atraente margem de lucro seriam capazes de empurrar essa expressão para a alma do comerciante alemão. Como decisiva dentre as duas, deve a série causal estética ser aquela a vigorar: a saber, o humor, a jocosidade e a ironia do comerciante alemão, como ele considera para si a hostil oferta linguística da expressão cujo significado amargo e original reverte-se em um novo e cuja pronúncia inglesa agora é preenchida com um espírito alemão, até mesmo com um ethos alemão - e agora, através

\footnotetext{
${ }^{4}[\ldots]$ alle Technik hat ihr Ideal. d. h. den Maßstab ihrer Richtigkeit, in sich selbst, nicht außerhalb, nicht oberhalb. [...] Überall wo es eine besondere Technik gibt, ist ein besonderer Gedanke, eine besondere Idee e o ipso vorhanden. Die Technik des Malers steht im Dienste eines malerischen, die des Musikers im Dienste eines musikalischen Gedankens. Darum steht die Grammatik als die Technik der Sprache in keinem anderen Dienste als in dem des sprachlichen und nicht des logischen Gedankens.

Jetzt wissen wir, in wessen Dienst die Lehre von der sprachlichen Richtigkeit, die praktische Grammatik steht. Sie arbeitet im Dienste der Sprache als Kunst, sie lehrt uns die Technik der sprachlichen Schönheit. Unter Geschmak pflegt man eher ein nachahmendes, wählendes und reproduktives als ein frei erfindendes, schöpferischer Kunstvermögen zu verstehen. Der Geschmack ist erziehungsfähig und erziehungsbedürftig, der schöpferische Genius ist - wenigstens insofern er originell produziert - weder das eine noch das andere. In concreto, d. h. beim lebendingen Menschen, finden sich produktives und reproduktives Kunstvermögen, Geschmack und Genie fortwährend und unzertrennlich verflochten. Nachahmung und Originalität, Meisterwerk und Stümperei liegen allenthalben durcheinander. Aufgabe der Kunstkritik ist es, sie zu sondern.
} 
desse mesmo espírito que penetrou no estrangeirismo, ele [o comerciante] pode começar a ter simpatia estética. (VOSSLER, 1923, p. 17-18, tradução minha) $)^{5}$.

$\mathrm{Na}$ enunciação monológica, segundo o autor alemão, manifesta-se o arbítrio do falante perante as escolhas estéticas disponibilizadas pela língua, arbítrio esse que está intimamente ligado à sua consciência individual, a verdadeira responsável pelas mudanças linguísticas de acordo com o próprio Vossler. A série causal prática seria o plano de fundo das ofertas linguísticas, enquanto a decisiva seria a série causal estética por ser aquela que irá ao encontro do desejo de expressão da consciência individual (o humor, a jocosidade, a ironia). A consciência encontra seu material expressivo nas formas linguísticas, remetendo a filosofia de Vossler, em grande medida, às teorias da expressão, como afirmado em MFL.

Sobre a influência do romantismo no pensamento do alemão, que é a nossa segunda questão, vejamos o seguinte trecho:

A produção linguística verdadeira e valiosa seria portanto aquela em que a forma se representa como a mais singular, exclusiva e individual e o conteúdo como o mais multifacetado, abrangente e universal. A mais exclusiva individualidade combinada com a mais inclusiva universalidade: este é o ideal do pensamento linguístico. É, como podemos facilmente notar, o ideal dos poetas, dos pintores, dos músicos, de todo artista. O pensamento linguístico é essencialmente poético; a verdade linguística é essencialmente artística, é o belo pleno de significado. Todos, enquanto produzimos estruturas linguísticas, somos como poetas e artistas, por mais que, na vida cotidiana, a maioria sejam artistas menores, medianos, fragmentários e não originais. É desnecessário considerar nossa fala cotidiana poesia ou arte. Contudo, as gotículas linguísticas de um tagarela são, afinal, tão boa água de Hipocrene quanto o infindável oceano de um Goethe ou de um Shakespeare. (VOSSLER, 1923, p. 14-15, tradução minha) ${ }^{6}$.

\footnotetext{
${ }^{5}$ Wenn der Deutsche von dem Engländer das Schlagwort made in Germany entlehnt und in seine deutsche Sprache hereinnimmt, so gibt es dafür zwei verschiedene Ordnungen von Gründen: eine praktische und eine ästetische Kausalreihe. Die praktischen Gründe sind diejenigen, die dem Deutschen das englische Schlagwort nahegebracht und angeboten haben. Es sind die Kräfte des grössten wirtschaftlichen Konkurrenzkampfes, den die Menschheit gesehen hat. Allein, dem deutschen Kaufmann dieses Schlagwort in den Mund zu schieben, das vermag weder Englands ganze Weltmacht, noch vermögen es die lockendsten Gewinnberechnungen in der Seele des deutschen Kaufmanns selbts. Es muss als ausschlaggebend die zweite, die ästetische Kausalreihe in Kraft treten: nähmlich der Humor, der Witz, die Ironie des deutschen Kaufmanns, wie er das feindselige Sprachangebot sich betrachtet, dessen bittere, ursprüngliche Bedeutung durch eine neue Deutung umkehrt, dessen englischen Laut mit deutschen Geiste, ja sogar mit deutscher Gesinnung erfüllt und nun durch diesen eigenen Geist hindurch mit der fremden Form ästetisch zu sympathisieren beginnt.

${ }^{6}$ Das wahre und wertvolle sprachliche Werk wäre demnach dasjenige, das formell als das eigenartigste, ausschließlichste und individuellste, inhaltlich als das vielseitigste, umfassendste und universalste sich darstellte. Ausschli e ßlichste Individualität vereignigt mit e inschlie ßlichster Universialität, das ist das Ideal des sprachlichen Gedankens. Es ist, wie man ohne weiteres sieht, das Ideal des Dichters, des Malers, des Musikers, jedes Künstlers. Der sprachliche Gedanke ist wesentlich dichterischer Gedanke, sprachliche Wahrheit ist künstlerische Wahrheit, ist bedeutungsvolle Schönheit. Wir alle, insofern wir sprachliche Gebilde erzeugen, wir alle sind Dichter und Künstler, freilich im gewöhnlichen Leben zumeist recht kleine, mittelmäßige, fragmentarische und unoriginelle Künstler. Es ist nicht der Rede wert, unser gewöhnliches Sprechen als Dichtung oder Kunst zu betrachten. Aber der winzige sprachliche Regentropfen eines Schwätzers ist schließlich gerade so gut Wasser aus Hippokrene wie der unendliche Ozean eines Goethe oder Shakespeare.
} 
Vossler classifica produções linguísticas como "verdadeiras e valiosas". Examinando seus argumentos, encontramos ecos do pensamento romântico e idealista manifestando-se na noção de autoria original e exclusiva.

A produção linguística relevante segue, para Vossler, os parâmetros de artes como a música e a pintura. Ele afirma que o poeta, o músico e o pintor perseguem o ideal da universalidade do conteúdo dentro da exclusividade da forma - esta, como compreendemos, consiste na marca autoral. O professor Antonio Candido (1988, p. 2), em aula inaugural ocorrida na PUC-RJ, elucida-nos que uma das forças do movimento romântico foi a "superação das normas literárias impessoais":

Foi no romantismo que se definiram algumas coisas ainda vigentes, como a superação das normas literárias impessoais. Antes dele, um professor poderia invalidar o trabalho de um aluno alegando que ele utilizou a palavra cachorro. Num soneto só se usava cão. Numa tragédia não existiam cavalos, só corcéis. Eram regras imutáveis, como a de que uma tragédia tinha que se passar em 24 horas. O romantismo acabou com essas regras constritoras, pesadas, que amarravam a prática literária e isso está ligado à ideia de liberdade.

Para aprofundarmos nossa discussão, comparemos a "ideia de liberdade" conferida ao romantismo por Antonio Candido com o seguinte trecho do professor da Universidade de Monique Detlef Kremer, destacado estudioso do romantismo alemão e em cujos escritos sobre a influência da filosofia idealista na literatura romântica basearemos nossa discussão:

Por volta do final do século XVIII, no romantismo e classicismo de Weimar, definiu-se uma literatura de vanguarda sob a asserção e justificativa de uma autonomia estética, em contraposição ao propósito das ciências e à função moralizante da literatura do Iluminismo. [...] A alegada autonomia da literatura romântica deve ser levada a sério, já que ela transformou, na poesia escrita, o sistema linguístico existente, e esse processo de metamorfose literária se refletiu e tematizou em seus próprios termos formais. (KREMER, 2015 , p. 89, tradução e grifos meus) ${ }^{7}$.

Nesse estudo, Kremer visa comprovar a autonomia estética "inaugurada" pelo romantismo na forma e no conteúdo. Para isso, analisa o que chama de quatro figuras básicas da poética romântica (Grundfiguren der Romantischen Poetik): a poesia universal progressiva (Progressive Universalpoesie); a teoria da imaginação (Theorie der Imagination); a autorreflexão (Selbstreflexion) e a mitologia nova ou moderna (Neue Mythologie). O movimento romântico, como um todo, projeta uma autonomia estética da literatura em relação a outras atividades humanas (libera a literatura de fins didáticos, por exemplo) e aponta para o florescimento da autoria na obra literária a partir do momento que quebra as regras impessoais. Neste artigo, vamos utilizar as considerações de Kremer sobre a poesia universal progressiva, tópico em que fica evidenciada a relação entre a

\footnotetext{
${ }^{7}$ Gegen Ende des 18. Jahrhunderts, in Romantik und Weimarer Klassik, definiert sich avancierte Literatur über die Behauptung und Begründung ästhetischer Autonomie im Unterschied zur Zweckbestimmung der Wissenschaften und zur moralischer Funktionalität der Aufklärung. [...] Die behauptete Autonomie der romantischen Literatur ist darin ernstzunehmen, dass sie das vorgegebene Sprachsystem in poetische Schrift verwandelt und diesen Vorgang literarischer Metamorphose immer auch in seinen formalen Bedingungen reflektiert und mitthematisiert.
} 
ideia de autoria no romantismo como consequência da ideia de sujeito formulada pelo idealismo.

Segundo Kremer, a formulação do postulado de autonomia da arte romântica consiste de um acordo entre a estética do idealismo alemão (Schelling e Hegel são por ele citados) e a poética do início do romantismo. Contudo, afirma o professor alemão que, diferentemente do idealismo, a estética romântica se apresenta não num sistema feito especialmente para ela, mas sim num conjunto de fragmentos. Kremer cita um desses fragmentos, de autoria de Friedrich Schlegel, em que é cunhado o termo "poesia transcendental" (Transzedentalpoesie), para ilustrar que esse movimento transcendente da poesia romântica é baseado no que ele chamou de "níveis de reflexão transcendentais" (transzendentale Reflexionsniveau) do idealismo alemão em sua fase inicial:

[238] Há uma poesia, cujo uno e todo expressa a relação entre o ideal e o real, e que de acordo com a analogia da linguagem artístico-filosófica pode ser chamada de Poesia Transcendental. Ela começa como sátira, com a absoluta diferenciação entre o ideal e o real; ao meio gravita pela elegia e termina como idílio, com a identidade absoluta de ambos [ideal e real]. Assim como o homem pouco valor colocaria em uma filosofia transcendental que não fosse crítica, não representasse a produção e o produto e que no sistema do pensamento transcendental não contivesse ao mesmo tempo uma característica do pensar transcendental, então deveria cada poesia unir os materiais transcendentais e premonições a uma teoria do gosto poético dotada de reflexão artística e de auto-reflexão estética - que nos poetas modernos não é raro, e que podem ser encontrados em Pindar, nos fragmentos líricos dos gregos, nas velhas elegias e sob os modernos, em Goethe $-\mathrm{e}$ cada uma de suas representações deve em si mesma se representar com, e acima de tudo ao mesmo tempo, poesia e poesia e da poesia. (SCHLEGEL, 1798, tradução e grifos meus $)^{8}$.

Tomemos por base as ideias de Hegel sobre o idealismo: resumidamente, na dialética hegeliana do espírito há uma consciência (Geist) que sai de sua fase original "em si" para travar contato com sua alteridade (outra consciência ou objeto) no mundo exterior objetivo, posteriormente retornando a si transformada dessa jornada. Diz Hegel (1970[1832-1845], p. 128, tradução minha) em seu curso de estética sobre a arte romântica que:

O espírito, que tem por princípio sua adequação consigo mesmo, a unidade de seu conceito e sua realidade, pode encontrar seu respectivo ser-aí apenas em seu locus e em seu próprio mundo ideal de sensações, mentalidade e sobretudo interioridade. [...]. A elevação do espírito para si, através da qual ele deve buscar sua objetividade (que está na exterioridade e na sensorialidade do ser-aí) e através da qual ele em si mesmo e nessa unidade consigo

\footnotetext{
${ }^{8}$ [238] Es gibt eine Poesie, deren eins und alles das Verhältnis des Idealen und des Realen ist, und die also nach der Analogie der philosophischen Kunstsprache Transzendentalpoesie heißen müßte. Sie beginnt als Satire mit der absoluten Verschiedenheit des Idealen und Realen, schwebt als Elegie in der Mitte, und endigt als Idylle mit der absoluten Identität beider. So wie man aber wenig Wert auf eine Transzendentalphilosophie legen würde, die nicht kritisch wäre, nicht auch das Produzierende mit dem Produkt darstellte, und im System der transzendentalen Gedanken zugleich eine Charakteristik des transzendentalen Denkens enthielte: so sollte wohl auch jene Poesie die in modernen Dichtern nicht seltnen transzendentalen Materialien und Vorübungen zu einer poetischen Theorie des Dichtungsvermögens mit der künstlerischen Reflexion und schönen Selbstbespiegelung, die sich im Pindar, den lyrischen Fragmenten der Griechen, und der alten Elegie, unter den Neuern aber in Goethe findet, vereinigen, und in jeder ihrer Darstellungen sich selbst mit darstellen, und überall zugleich Poesie und Poesie der Poesie sein.
} 
mesmo se sente e se dá a conhecer para si, consiste no princípio fundamental da arte romântica. ${ }^{9}$

Na dialética hegeliana há uma consciência a priori e destacada da matéria. Em suas "idas" ao mundo da forma, torna-se "ser-aí", que seria a materialização de um dos momentos do espírito num espaço e tempo determinados, ou seja, é o espírito historicamente manifestado, porém, cuja existência precede a materialização na forma. O ser-aí, momento em que o espírito se exterioriza e se torna sensorial, trava contato com a alteridade no mundo objetivo. Esses momentos são vários e finitos, visto que a única eternidade possível ocorre quando o espírito está adequado a seus próprios princípios (em sua interioridade). Os repetidos momentos de exteriorização do espírito e sua volta a si mesmo produzem dialeticamente sua elevação (imaginemos a figura de uma espiral ascendente), na qual ele reflete sobre si mesmo; contudo, quanto mais vive na objetividade, mais o espírito se dá conta de que não é compatível com ela, não podendo ser pleno em outro lugar senão em sua própria interioridade, para a qual sempre retorna.

Essa noção de sujeito não subordinado à matéria, mas acima dela e que tenta por meio dela - falidamente - se expressar (visto que sua existência verdadeira só ocorre em sua própria mentalidade) ${ }^{10}$, implica que o conteúdo a ser expresso por esse sujeito está igualmente "fora" e acima do mundo concretamente manifestado, sendo a forma apenas seu veículo - não a determinante de seu conteúdo. Hegel defende todo um sistema filosófico em que a consciência é criadora da realidade manifesta no mundo; inclusive, defende que as entidades sociais como o Estado e mesmo os papéis sociais dos gêneros masculino e feminino espelham a estrutura dessa consciência. ${ }^{11}$ Para o filósofo, a marca da autoria do espírito abrange toda a gama de manifestações materiais, não exclusivamente a estética, pois o espírito é soberano sobre a materialidade, sendo esta um pálido reflexo seu.

Segundo Kremer pontua, Schlegel, um dos grandes românticos, tem plena sintonia com a dialética e a noção de sujeito hegelianas (aqui brevemente apresentadas), pois demanda que a poesia romântica seja uma combinação de composição artística com a autorreflexão teórica (lembrando-nos do espírito que reflete sobre si mesmo): "A tônica subjetiva da imaginação romântica incluída aqui corresponde a uma forma de dupla reflexão, que primeiramente significa reflexão do mundo e, posteriormente, autorreflexão" (KREMER, 2015, p. 91). Encerrando o tópico da poesia universal progressiva, o professor reafirma a conexão de Schlegel com a filosofia idealista: "o conceito de poesia transcendental de Schlegel convida-nos a cruzar fronteiras recíprocas, à mistura de poesia e filosofia" (idem).

\footnotetext{
${ }^{9}$ Der Geist, der die Angemessenheit seiner mit sich, die Einheit seines Begriffs und seiner Realität zum Prinzip hat, kann sein entsprechendes Dasein nur in seiner heimischen, eigenen geistigen Welt der Empfindung, des Gemüts, überhaupt der Innerlichkeit finden. [...] Diese Erhebung des Geistes zu sich, durch welche er seine Objektivität, welche er sonst im Äußerlichen und Sinnlichen des Daseins suche mußte, in sich selber gewinnt und sich in dieser Einigkeit mit sich selber empfindet und weiß, macht das Grundprinzip der romantischen Kunst aus.

${ }^{10}$ Como no aforismo do famoso autor Friedrich Schiller (10/11/1759 - 08/05/1805), um dos fundadores do postulado romântico: Por que o espírito vivo não consegue seu espírito manifestar? Ao falar a alma, ah! já não fala a alma mais (Warum kann der lebendige Geist dem Geist nicht erscheinen? Spricht die Seele, so spricht ach! schon die Seele nicht mehr), contido em sua obra Tabulae Votivae, de 1797. Tradução minha.

${ }^{11}$ Assunto desenvolvido na obra Fenomenologia do Espírito (Phänomenologie des Geistes).
} 
O trabalho de Kremer nos permite ver que o romantismo afina-se com o idealismo quando concebe um sujeito que é único/original, uno em si mesmo e criador da realidade. Esse sujeito livre das determinações da matéria coincide com a autonomia na criação literária romântica em dois âmbitos: em relação a outras atividades, postulando a autonomia estética citada por Candido e Detlev, e em relação à expressão de marcas autorais individuais, que entram no lugar das prévias "regras constritoras" referidas por Candido em 1988.

Vossler herda fortemente essa dupla influência romântico-idealista. Comparemos o trecho grifado do fragmento [238] de Schlegel com este, no qual o linguista alemão declara embasar sua filosofia da linguagem em outra teoria do gosto, o linguístico: "Portanto, este é o ponto da virada (para a filosofia da linguagem): toda mudança e desenvolvimento linguísticos são, em última instância, trabalho do gosto ou intuição linguísticos do falante" (VOSSLER, 1923, p. 15-16, tradução minha). ${ }^{12}$ Esse trecho evidencia o eco da concepção romântico-idealista na teoria do gosto linguístico, que é simultaneamente expressão do livre arbítrio e da reflexão artística/estética que cada falante traz potencialmente dentro de si.

Todos os elementos analisados nesta seção culminam na preleção do monólogo autoral como material da investigação linguística para Vossler, que acreditava serem as escolhas lexicais e semânticas do falante reflexos de seu estilo, além de dar acesso aos motivos e impulsos da consciência individual. Nesta seção, pontuamos marcas da influência do pensamento romântico na Filologia Idealista Moderna e em que medida esta raiz romântica e idealista subjaz à noção do monólogo e sustenta a nossa adjetivação "autoral".

\section{O heterodiscurso social: a perspectiva assumidamente dialógica}

O Círculo de Bakhtin, com seu método sociológico, traz um olhar dialógico em relação ao discurso. Bakhtin dedica-se especificamente ao romance por ser o modelo narrativo que, segundo ele, permite e evidencia em sua estrutura a coexistência das (por ele denominadas) várias "línguas sociotípicas". Segundo ele, estas línguas são discursos e formas socioideologicamente contraditórias entre si, entre o presente e o passado, entre diferentes épocas do passado, entre correntes e escolas etc. que exercem, em relação à língua "oficial" e a seu correspondente mundo ideológico verbalizado, uma força centrífuga descentralizante.

Segundo Bakhtin, a língua "oficial", para cumprir sua função de unificar a identidade nacional de um povo, opera como uma força centrípeta centralizadora. Para ele, a língua na poesia cumpriu tal papel na identidade nacional; por outro lado, as demais línguas sociotípicas existentes numa comunidade exercem força inversa à língua oficial, tendo a estrutura narrativa do romance desenvolvido uma representação da linguagem capaz de acomodá-las: o heterodiscurso social, definido por Bakhtin (2015, p. 42-43) como "o arremedo de todas as línguas e dialetos" da vida centrífuga da língua. Os estudiosos Ida Lucia Machado e João Marcos Cardoso de Sousa (2011, p. 122), apoiados na ideia do dialogismo, afirmam que:

\footnotetext{
${ }^{12}$ Denn, dies ist der entscheidende Punkt, alle sprachliche Wandlung und Entwicklung ist, in letzter Instanz, das Werk des Geschmackes oder Kunstgefühles der Sprechenden.
} 
[...] o enunciado é, fundamentalmente, sulcado por inúmeros sujeitos e gêneros que se conciliam num embate e acordo de forças para eleição do um no ato comunicacional para possibilitar sentido e comunicação. Todavia, o um não é puro, inteiro e completo de si mesmo ou de sua imagem; trata-se do um impregnado do outro ou dos outros que já habitam a totalidade do campo subjetivo da enunciação e, consequentemente, do discurso.

Segundo a visão dialógica do enunciado, o heterodiscurso social remete-nos para fora do campo literário: cada língua sociotípica organiza um mundo ideológico diverso e cada enunciado é uma preleção de uma imagem do "eu" dentre várias, todas impregnadas da imagem e do discurso do "outro". Contrapõe-se, por isso, à nossa definição de monólogo autoral, termo que cunhamos para representar a ideia vossleriana do gosto e/ou gênio linguísticos do falante como determinantes do conteúdo verbal a ser exprimido por este.

Comparemos ambas as abordagens para termos mais clareza da diferença fundamental entre a base monológica idealista e a dialógica marxista: Vossler não ignora a existência e mesmo a importância do diálogo. Na complexidade de sua filosofia da linguagem, Vossler (1923) não teoriza apenas sobre a natureza das mudanças linguísticas, mas também sobre a fala coloquial (Umgangssprache), que em sua fase mais elaborada e mais próxima do trabalho artístico da linguagem torna-se, segundo ele, o que se chama de "eloquência" (Beredsamkeit). Tanto uma quanto a outra são, diz o alemão, essencialmente dialógicas, pois podem ser divididas em ciclos ininterruptos (Kreislauf) dos momentos de fala (Sprechen), escuta (Hören), compreensão (Verstehen) e resposta (Wiedersprechen/Antworten) ou em papéis (Rollen) entre indivíduos ou dentro da própria consciência individual. Vossler afirma sequer ser possível ou relevante elencar se o monólogo antecede o diálogo ou vice-versa.

O monólogo autoral parece, para ele, ser o produto final desse processo interior do indivíduo; contudo, por mais que Vossler admita esse processo interior como dialógico, não chega a considerá-lo como a composição de ideologias e construções linguísticas nascidas no seio da interação social. A diferença essencial de Vossler para os autores do Círculo em questão parece-nos dizer respeito ao fato que Vossler considera o indivíduo soberano sobre a construção e a expressão linguísticas de seu próprio ethos, indo no caminho inverso do "eu" que emerge de vários "outros" num enunciado assumidamente dialógico (como definido por Machado e Sousa).

Por outro lado, Bakhtin teoriza sobre as línguas sociotípicas de diferentes comunidades de fala que, em suas próprias palavras, remetem a diferentes pontos de vista específicos sobre o mundo, a formas de compreensão verbalizada, a horizontes concretosemânticos e axiológicos específicos. Como remetem a um universo fora delas mesmas, essas línguas podem ser correlacionadas dialogicamente, ou seja, podem ser confrontadas, completar-se ou contradizer-se umas às outras. É verdade que elas existem na consciência do ser humano individual, porém não podem ser desligadas do nível coletivo, pois são fragmentos reais da luta de classes disposta no heterodiscurso social. Para Bakhtin, essas línguas habitam, também, a consciência artística e criadora da humanidade; contudo, diz que a consciência e suas formas expressivas não são soberanas sobre o material sígnico com o qual operam: ao contrário, dele emerge o discurso interior, responsável em grande medida pelo sentido de individualidade de cada sujeito.

Para o autor russo, a consciência pode orquestrar, mas não compor sentidos intrínsecos à interioridade do indivíduo (como acreditava Vossler que o falante individual, 
o grande responsável pelas mudanças linguísticas segundo seu gosto ou gênio, era capaz). Os sentidos são criados constantemente pelas diversas línguas nascidas no seio da interação social, frequentemente em embate em si. No romance, tais línguas são orquestradas pelo autor de modo a representar ou refratar suas próprias intenções e avaliações numa personagem ou num narrador.

Seguindo o lançamento da filosofia da linguagem marxista, Bakhtin (2015, p. 21) pretendeu lançar uma estilística sociológica, "para a qual a forma e o conteúdo são indivisos no discurso concebido como fenômeno social". A aplicação que o autor faz do método sociológico na análise estilística veremos a seguir.

\section{Estilística e estilo: análise comparativa entre a base dialógica do Círculo de Bakhtin e a base monológica da Filologia Idealista Moderna}

Neste tópico, faremos a contraposição do método monológico da escola de Vossler ao método dialógico do Círculo. Veremos como os conceitos de monólogo autoral e heterodiscurso social expressam o diferencial teórico essencial entre as concepções de ambas vertentes através de uma seleção de análises em que Vossler e Bakhtin aplicam suas respectivas bases teóricas. Por fim, poderemos concluir como a base dialógica do Círculo sinalizou um dos momentos de transição na investigação linguística.

Comecemos com uma análise de estilo que Vossler faz baseada na gramática, que para ele consistia na "técnica da língua". Como metodologia, Vossler divide sua análise nas seguintes dicotomias: analítica $\mathrm{x}$ sintética (analytischem $x$ synthetischem), descritiva $\mathrm{x}$ narrativa (beschreibendem x erzählendem) e explicativa e interpretativa (erklärendem $x$ deutendem). Essas seriam, para ele, características essenciais do que ele denominou a vertente do pensamento francês (de Montesquieu a Taine), mais analítica, descritiva e explicativa, em contraposição à romântica (de Vico a Herder e Hegel), mais sintética, narrativa e interpretativa. Ele utiliza essas características para reconhecer movimentos (ou momentos) literários através de escolhas gramaticais que expressam tendências estilísticas particulares:

Como na maioria das línguas romances, o francês escrito possui duas formas flexíveis distintas para designar o passado: o imperfeito (Imparfait) e o passado simples (Passé défini). Àquele corresponde uma percepção do passado analítica, descritiva, explicativa e até mesmo estática; a este, uma dinâmica, sintética, narrativa e interpretativa. [...] O estado literário normal, ou pelo menos o uso clássico, é a tranquila cooperação de ambos no estilo da narrativa. Se a leitora ou o leitor querem experienciar e compreender como o passado simples pode ser belamente usado para o progresso da ação [...] e como, por outro lado, o imperfeito serve para ilustrar circunstâncias do entorno [...], então que tenha o prazer de ler alguma das fábulas de LaFontaine, o maior narrador francês. Depois, que compare e perceba como outros poetas narram as mesmas fábulas com tempos totalmente diferentes, ou pelo menos variados, para que sua percepção se atente para a presença do gênio artístico ou do gosto ou temperamento artístico - em resumo, fatores estéticos individuais que eclodem nesta passagem. Um possui um olhar estático, o outro dinâmico sobre as coisas. Nos romances de Zola (representante do naturalismo francês) tudo é 
concebido no imperfeito; já nas narrativas medievais, no passado simples. (VOSSLER, 1923, p. 43, tradução minha) ${ }^{13}$.

Vossler atribui as escolhas gramaticais estilísticas ao estilo pessoal de cada autor, que reflete o gosto ou temperamento linguístico de seu gênio criador: neste caso, o emprego de determinado tempo verbal refletiria que um autor "possui um olhar estático, o outro dinâmico sobre as coisas". Sua concepção de produção linguística não considera a influência que a recepção da obra poderia exercer sobre sua composição, nem mesmo vozes distintas daquelas do autor e seu gênio pessoal que pudessem povoar sua criação; o que Vossler busca é mapear como esse gênio expressa-se e cria seu estilo através de uma "bela composição" gramatical, que para ele é algo muito próximo ao gosto linguístico.

Para Bakhtin, o romance deixa de ser apenas uma obra onde uma figura autoral concatena esteticamente seu monólogo para ser o espaço onde a prosa alcança concatenar o heterodiscurso social, representante das línguas sociotípicas e seus diferentes mundos verboideológicos:

O heterodiscurso introduzido no romance (quaisquer que sejam as formas de sua introdução) é o discurso do outro na linguagem do outro, que serve à expressão refratada das intenções do autor. A palavra de semelhante discurso é uma palavra bivocal especial. Ela serve ao mesmo tempo a dois falantes e traduz simultaneamente duas diferentes intenções: a intenção direta da personagem falante e a intenção refratada do autor. Nessa palavra há duas vozes, dois sentidos e duas expressões. Ademais, essas duas vozes são correlacionadas dialogicamente, como que conhecem uma à outra (como duas réplicas de um diálogo, conhecem uma à outra e são construídas nesse conhecimento recíproco), como se conversassem uma com a outra. A palavra bivocal é sempre interiormente dialogada. Assim é a palavra humorística, prosaica, paródica, assim é a palavra refratadora do narrador, que refrata a palavra nas falas do herói e, por último, a palavra do gênero intercalado: tudo isso são palavras bivocais interiormente dialogadas. Nelas está fixado o diálogo potencial, não desenvolvido, o diálogo concentrado de duas vozes, de duas visões de mundo, de duas linguagens. (BAKHTIN, 2015, p. 113).

Examinemos alguns exemplos de heterodiscurso disseminados em Turguêniev.

Exemplo 1 (Pais e filhos):

\footnotetext{
${ }^{13}$ Wie die meisten romanischen Sprachen, so besitz auch das Schriftfranzösische für die Bezeichnung der Vergangenheit zwei verschiedene flexivische Formen, das Imparfait und das pásse défini. Jedem entspricht eine analytische, beschreibende, erklärende, man könnte auch sagen, eine statische Auffassung der Vergangenheit, diesem eine dynamische, synthetische, erzählende, deutende. [...] Der normale literarische Zustand oder wenigstens der klassische Usus ist freilich das friedlich Zusammenwirken von Imparfait und Pásse Défini im Stile der Erzählung. Will man handgreiflich erleben und verstehen, wie schön das Pásse défini verwendet werden kann, um eine Fortschritt der Handlung, [...] und wie andererseits das Imparfait sich eignet, um die Nebenumstände [...] zu veranschaulichen, so mache man sich das Vergnügen und lese einige Fabeln des LaFontaine, des größten französischen erzählers. Vergleicht man dann und bemerkt, wie andere Dichter dieselben Fabeln mit völlig verändertem oder wenigstens abweichendem Tempus-gebrauch erzählen, so kann man sich der Einsicht nicht verschließen, daß es das künstleriche Genie ist oder der künstlerische Temperament, kurzum ästherischen Faktoren individualler Art, die hier den Ausschlag geben. [...] der eine hat eine statisch, der andere eine dynamisch eingestellte Anschauung der Dinge. In Zolas Romanen wird alles zum Imparfait, in den mittelalterlichen Erzählungen alles zum Pásse Défini.
} 
"Ele se chama Nikolai Pietróvitch Kirsánov. A quinze verstas da hospedaria ele tem uma fazenda com duzentas almas ou adquiriu uma 'chácara' de duas dessiatinas de extensão, como ele mesmo se exprime desde que dividiu suas terras com os camponeses."

Aqui foram tomadas entre aspas ou depreciadas as novas expressões características da época em estilo liberal.

Exemplo 2 (Pais e filhos):

"Ele começava a sentir uma secreta irritação. Indignava sua natureza aristocrática, o desembaraço absoluto de Bazárov. Esse filho de médicos não só não se acanhava como até respondia de modo descontínuo e a contragosto, e nos sons de sua voz havia qualquer coisa de grosseiro, quase descarado."

A terceira oração desse parágrafo (grifos nossos), sendo por seus traços sintáticos formais parte do discurso do autor é, ao mesmo tempo, pela escolha das expressões ("esse filho de médico") e por sua estrutura expressiva, um dissimulado do discurso do outro (Pável Pietrovitch). (idem, p. 102-103).

Vemos que o heterodiscurso social enriqueceu expressivamente o discurso literário: enquanto o monólogo autoral de Vossler focava-se em analisar e apreciar os tons do temperamento do gênio criador, expressos através de suas escolhas gramaticais, a partir do momento em que Bakhtin reconhece a palavra como bivocal, ela passa a representar não apenas o discurso direto de seu autor como também o discurso refratado (seja do narrador nas palavras de outrem, ou do outro nas palavras do narrador ou do herói). A composição gramatical passa, então, a representar mais do que a técnica do belo: ela concatena as diferentes vozes discursivas presentes na sociedade.

Portanto, a análise literária deixa de ser apreciativa de uma visão de mundo particular e específica do gênio e passa a reconhecer as várias visões de mundo infiltradas numa única sentença - e o consequente confronto social que ali se revela. $\mathrm{O}$ uso da ironia, jocosidade e outras figuras de linguagem, que Vossler afirmava estarem a serviço da expressão da consciência de um indivíduo e seu ethos, ganha profundidade ao ser relacionado com os vários discursos que representam as várias consciências expressas nas línguas sociotípicas (como o "chácara", que naquele contexto específico revela a ascensão de uma organização social liberal num mundo ainda aristocrático, contexto no qual claramente o termo não estava bem ambientado e indicava uma mudança nas relações sociais).

A dialogia proposta pelo método sociológico permite à análise estilística um âmbito maior de sentidos do que a análise monológica poderia levar o crítico - assim como a leitora e o leitor - a produzir. A transição do olhar monológico de Vossler para o dialógico, representado aqui pelo heterodiscurso social, abre caminho para correlacionar a obra com a sociedade em cujo seio a interação produziu, para um determinado signo, um determinado significado num determinado tempo e espaço: "uma palavra nos lábios de um único indivíduo é um produto da interação viva das forças sociais" (VOLOCHINOV, 2017[1929], p. 140) 


\section{Considerações finais}

Bakhtin/Volochinov afirmam que sua filosofia da linguagem dialógica, apoiada no método sociológico, vem a ser a síntese dialética que expressa recusa da tese, a escola de Vossler. Neste artigo, demonstramos que sua caracterização da base românticoidealista monológica de Vossler é procedente, e que o dialogismo empregado na análise do discurso trouxe uma mudança significativa e um enriquecimento da análise estilística e da concepção de estilo não por passar a reconhecer a existência do diálogo, mas por torná-lo base da análise linguística e estilística, inclusive da produção individual e autoral literária.

Para Vossler, o estilo, exercido através do gosto linguístico, era a expressão, na construção linguística, da soberania do indivíduo sobre o material social oriundo do diálogo, e como resultado a análise estilística buscava o belo por trás da construção gramatical. $\mathrm{O}$ discurso literário estilístico era admitido, portanto, como monológico e autoral, fruto de peculiaridades do gênio criador. Para o Círculo, o discurso passa a ser visto como inevitável e sensivelmente permeado por várias línguas sociotípicas, cuja expressão de visões de mundo divergentes e conflitantes são detectáveis pela concatenação de várias vozes expressas num enunciado que é apenas superficialmente individual, mas que na verdade contém a voz da alteridade em sua estrutura e reflete e refrata a própria interação social, em constante contradição e conflito. A novidade da análise estilística dialógica é justamente reconhecer que um enunciado não é uníssono; ao contrário, a palavra é bivocal. Num (aparente) monólogo, é possível detectar diversas línguas que representam, constroem e fazem interagir variados sentidos e referências ideológicas.

Tudo isso está contido no heterodiscurso social, fortemente representado na estrutura da narrativa romanesca. Para o método sociológico, o estilo passa a marcar "a liberdade do autor em relação a uma língua única e singular, vinculada à relativização dos sistemas de linguagem literária", que "marcam a possibilidade de autodeterminar-se em termos de linguagem, de transferir suas intenções de um sistema de linguagem a outro, de fundir 'a língua da verdade' com a 'língua do ambiente', de dizer o que é seu em linguagem alheia e em sua linguagem o que é alheio" (BAKHTIN, 2015, p. 100).

Ao descaracterizar a produção linguística como fruto do gosto linguístico de um indivíduo criador para revelar os variados discursos sociais contraditórios existentes num mesmo enunciado, o maior papel dos teóricos do Círculo de Bakhtin foi alcançar o entendimento de que o romance não é a representação direta do homem e sua consciência, como pretendeu Vossler, e sim a representação das línguas e dos discursos alheios. Diz Bakhtin (2015, p. 128-129, grifo do autor):

O que caracteriza o gênero romanesco não é a representação do homem em si, mas exatamente a representação da linguagem [...] o problema central da estilística romanesca pode ser formulado como o problema da representação literária da linguagem, o problema da imagem da linguagem.

Passando por questões intrínsecas ao olhar monológico e dialógico, como as diferentes concepções de sujeito e dos enunciados por ele produzidos, encerramos aqui nossa discussão sobre estilo e estilística nas vertentes idealista de Karl Vossler e marxista do Círculo de Bakhtin. 


\section{REFERÊNCIAS}

BAKHTIN, M. Teoria do romance I: A Estilística. Tradução de Paulo Bezerra. São Paulo: Editora 34, 2015.

CANDIDO, A. O Romantismo, nosso contemporâneo. Resumo da aula inaugural no Departamento de Letras da PUC-Rio. Jornal do Brasil, 19 mar. 1988.

HEGEL, G. W. F. Werke 14: Vorlesungen über die Ästhetik II. Frankfurt am Main: Suhrkamp Verlag, 1970.

KREMER, D. Romantik. Suttgart: J. B. Metzler Verlag, 2015.

MACHADO, I. L.; SOUSA, J. M. C. de. A função transgressiva dos múltiplos sujeitos nos gêneros discursivos. Bakhtiniana, São Paulo, 6 (1), p. 111-128, ago./dez. 2011.

PUZZO, M. B. Dialogismo bakhtiniano e a estilística vossleriana. Bakhtiniana, São Paulo, 12 (1), p. 134-153, jan./abr. 2017.

SCHILLER, F. Tabulae Votivae. Disponível em: <http://haab-digital.klassikstiftung.de/viewer/image/920186718 1797000000/110/>. Acesso em: 30 abr. 2017.

SCHLEGEL, F. Athenäums Fragmente. Disponível em: <www.zeno.org $>$. Acesso em: 01 mar. 2017.

VOLÓCHINOV, V. N. Marxismo e filosofia da linguagem: problemas fundamentais do método sociológico na ciência da linguagem. Tradução de Sheila Grillo e Ekaterina Vólkova Américo. São Paulo: Editora 34, 2017.

VOSSLER, K. Gesammelte Aufsätze zur Sprachphilosophie. Munique: Max Hueber Verlag, 1923.

Recebido em: 17/08/2017

Aprovado em: 14/03/2018 